\title{
Clash of Civilisations in Defining the Concept of Business Teacher Education Programme in Nigeria
}

\author{
Pac Ordu \\ School of Business Education \\ Federal College of Education (Technical) \\ P. M. B. 11, Omoku, Rivers State
}

\section{Doi:10.5901/mjss.2013.v4n16p9}

\section{Abstract}

What seems to be a conventional trend in employment of teaching staff into business education departments has posed a great threat to teaching and learning in the programme. The application of the word 'business' having been misinterpreted by education administrators opened the way to employing all sorts of graduates as teachers in business teacher education departments. This paper examines the role of education in the society and the role of quality assurance in the administration of business teacher education programme. A population of 52 lecturers of business education departments was studies with a view to sampling 20 lecturers for the study. The internal consistency of the instrument was 0.74 . Mean ratings and test retest statistics were used in analyzing data collected from the field. The paper highlighted the various courses and qualifications that are found in business education departments. It was revealed that some qualifications of lecturers in business education are preferred as traditional lecturers of the department while others are preferred as service course lecturers to the department. Based on the findings, it was recommended that holders of higher degrees in business education should be engaged as departmental lecturers while others whose degrees are not in business teacher education should be engaged as service lecturers.

\section{Introduction}

Education from primitive age has continued to play a significant role in the life of man and his style of living. Bearing in mind that man's own skills alone were not necessarily sufficiently to keep his generations economically going, the primitive man sought to engage some of his children in other trades and apprenticeship schemes. This was how man started his educational careers and provided for himself, with emphasis on progressive development on various fields, the vocations and disciplines that we enjoy today. Since then, Ordu (2013) informed that education has been rated as a useful tool for self-development and the development of societies. This may account for the reason why some societies have gone ahead of others in their developmental strands, and at the international level, some are rated as developed, others as developing, yet others as underdeveloped.

The developed societies appeared to have had the foresight in terms of measuring the role education was likely to play in their survival, and went ahead to capture it with all amount of jealousness and impunity. The case of developing societies was that they saw themselves as watchers of events created by developed societies. Realising that they too could have had something that others would watch, they decided to trail the ladder in the hope that as developed societies step out of a particular attractive-position, they could fill such vacuum. But unfortunately, the underdeveloped societies found no interest in the race between the first two societies thereby creating for themselves another race-line leading to consistent stay along the poverty line created by these two societies.

In Nigeria nation of recent past, education had been a useful tool of our developmental strands. The missionaries who came and colonized our indigenous system brought with them their education and 
introduced it as a weapon for wisdom and of development. They jettisoned our vocational education that had been consistent with our developmental local contents, and introduced their western education and culture that were totally foreign to our people and pattern. Our people who were educated through their system imbibed colonial mentality patterned in their own cultural arrangements thereby becoming graduates of literary subjects. Aside from literary subjects, these colonial masters invested in developing skills that were relevant to trade and commerce to support their missionary and commercial activities. This venom of colonialism was injected in our system that even as Nigerian administrators took over the mantle of selfgovernance at independence in 1960, the focus of education handed down to them by colonial masters was not jettisoned in favour of the application of local contents. The development of desired goals for our traditional and vocational education was therefore sacrificed on the altar of literary western educational culture.

The activities of commerce continued to develop along their pattern until business education evolved as a discipline consequent upon its relevance in business and commercial activities. Business education is offered as a discipline in tertiary institutions some of which have risen to awarding doctoral degrees. Today, Nigeria has produced scores of bright professors from business education discipline whose contributions to education are internationally referenced. Business education programme admits, trains, and produces those who wish to teach business subjects as well as those who wish to engage in various strands of business activities. Teachers of business subjects are found at all levels of educational settings in Nigeria although the category of qualifications possessed by an individual determine the educational level he is expected to teach. For those who wish to work in the commercial and business world, there are two distinctive strands to choose from. There are those who educate themselves for the purpose of working for paid employment; and those who receive their education for the purpose of self-employment.

Okoli (2010) explained that business education emphasizes two major trusts - (a) education for business, and (b) education about business. Under education for business, it is aimed at preparing recipients to be intelligent consumers of goods and services. The educational trust about business means the preparation of recipients for acquisition of skills that are necessary for paid employment, as well as the skills and competencies that are necessary to be self-employed as an entrepreneur. The totality of this trust was vividly captured, in part, in the 2012 National Council for Colleges of Education (NCCE) objectives of Nigeria Certificate of Education (NCE) business education programme thus:

a. To produce well qualified and competent NCE graduates in business subjects who will be able to teach business subjects in our secondary schools, and related educational institutions;

b. To equip graduates with the right skills that will enable them to engage in a life of work in the office as well as for self-employment.

Correspondingly, this objective in teaching and learning cannot be achieved where there is clash of interests between and among the administrators of business education programme. While those who possess teacher education qualifications attempt to explain the meaning of these objective items in their own rights, others whose qualifications are not business teacher education give contradictive interpretations. This variation in interpretation of the same curriculum and same contents leads to poor implementation of programme objectives. Departments held the view that the term 'business education' is related to them and therefore should be managers of the association. Those whose qualifications are from business administration and related departments opted for a more level playing ground and embracing formula towards integrational model even if that would mean modifications of this present nomenclature. This situation was vividly observed at the Benin 2013 Annual Conference of Association of Business Educators of Nigeria (ABEN). Those who trained from teacher education

\section{Statement of the Problem}

In some of our tertiary institutions offering business education programme, business teacher education has 
been misrepresented in Nigeria educational culture. In some of these institutions, you find all sorts of qualifications of teaching staff claiming to be authorities in business teacher education programme irrespective of the disciplines that they graduated from. Due to the fact that these lecturers coming from various related disciplines are more in number than those who possess business teacher education qualifications, they pose as traditional business teacher educators in business teacher education programme thereby intimidating those whose qualifications are in business teacher education disciplines. Extreme cases are very visible in situations where those who graduated as economists from Arts and Social Science departments with B.Sc and MSc, as well as those from Business Administration with MBA degrees, in addition to those with MBA in Banking and Finance, etc, establish themselves as superior members of business teacher education departments of core education programme offering institutions. These maverick lecturers, having found themselves as administrators in these departments misinterpret academic programme and conceal vital academic information simply to keep their jobs at the expense of academic realities. Having found themselves in some administrative positions, they maliciously visit with impunity, anybody's opinion who challenges the genuineness of their qualifications in business teacher education programme.

Considering the role of business teacher education in the development of societies especially in the implementation of innovation in education, it is necessary to find out some courses that are productive in the programme as well as quality of teaching staff that are relevant in business teacher education programme. This is necessary bearing in mind that all sorts of certificate holders are found teaching in the programme and claiming to be professionals in the same programme.

\section{Purpose of the Study}

To find out the qualifications that are necessary for holders to pose as authorities and professionals in business teacher education programme, this study is aimed at finding out some courses that are productive in teaching and learning in business education programme as well as quality of teaching staff that are professionally relevant to teach in the programme. Specifically, the study sets out to:

1. Find out which courses are preferred as major subsets of teaching and learning in business education programme.

2. Find out the qualifications of teaching staff to be referred to as business educators in business teacher education programme.

\section{Research questions}

The following research questions were posed to guide the study:

1. Which of these courses would you prefer as major subsets in the course listing of teaching and learning of business teacher education programme?

2. Which of these qualification holders would you prefer to be defined as a business educator in business teacher education programme?

\section{Methodology}

Since the method of research involves getting opinions of respondents over certain issues, the researcher adopted a descriptive survey design. Nworgu in Akuma and Igu (2011) explained that a descriptive survey research is one that a group of people are studied by collecting and analyzing data from only a few people considered to be representations of his entire group. The population of this study comprised one lecturer from each business education department of Nigerian tertiary institution who attended the annual conference of business educators held at Benin in 2013. This number represented 52 institutions that were randomly 
selected at the annual conference. The sample was 20 lecturers representing 20 business education departments of 20 tertiary institutions in Nigeria. The instrument for data collected was a 23 item questionnaire structured in this order: very highly productive (VHP) 4; highly productive (HP) 3; less productive (LP) 2; and very less productive (VLP) 1. The instrument was validated by two experts in measurement and evaluation from School of Education, Federal College of Education (Tech), Omoku. This validation exercise gave rise to some modifications of the instrument. The reliability of the instrument was established with application of test-retest method using some business educators at Federal College of Education (Tech), Omoku who were not to attend the 2012 ABEN conference. The result was subjected to Conbach alpha statistics to determine the internal consistency of the questionnaire. The coefficient alpha value of 0.75 was obtained which indicated an excellent stability.

The instrument was administered to the sampled respondents on the first day as they arrived the ABEN Conference venue and collected the second day at the same Conference venue. The data from research questions were analyzed using mean scores. All items with a mean of 2.50 and above were considered significant while items with less than a mean of 2.50 were considered insignificant and therefore rejected.

\section{Results analysis}

\subsection{Research question 1:}

Which of these courses are preferred as major productive subsets in the course listing of teaching and learning of business education programme.

Table 1: Mean score of business teachers perception of productive knowledge and skill competencies in teaching and learning in business education programme

\begin{tabular}{|l|l|c|c|c|c|c|c|c|}
\hline \multicolumn{1}{|c|}{ Classification } & VHP4 & HP3 & LP2 & VLP1 & Total & Sum & Mean \\
\hline 1 & Acquisition of typewriting skills & 2 & 6 & 5 & 7 & 20 & 43 & 2.15 \\
\hline 2 & Acquisition of shorthand skills & 1 & 2 & 7 & 10 & 20 & 34 & 1.70 \\
\hline 3 & Acquisition of computer associated programme skills & 9 & 6 & 4 & 1 & 20 & 61 & 3.05 \\
\hline 4 & Acquisition of entrepreneurship knowledge and skills & 11 & 5 & 2 & 2 & 20 & 65 & 3.25 \\
\hline 5 & Acquisition of economics knowledge & 2 & 4 & 9 & 5 & 20 & 43 & 2.15 \\
\hline 6 & Acquisition of management knowledge & 3 & 2 & 8 & 7 & 20 & 41 & 2.05 \\
\hline 7 & $\begin{array}{l}\text { Acquisition of business education programme course knowledge and } \\
\text { skills }\end{array}$ & 10 & 6 & 3 & 1 & 20 & 65 & 3.25 \\
\hline
\end{tabular}

Key: VHP = Very Highly Productive; HP = Highly Productive; LP = Less Productive; VLP = Very Less Productive

Analysis in Table one reveals that while 2.15 favoured the use of typewriters as productive in teaching and learning business education, 1.70 favoured shorthand skills acquisition as productive. Furthermore, the table also reveals that while 2.15 favoured the continued skills acquisition of economics courses as productive, only 2.05 favoured acquisitions of management knowledge courses as productive. Data in this table further shows that 3.05 indicated skills acquisition of computer associated courses as productive, 3.25 of the sample favoured skills acquisition of entrepreneurship courses, as 3.25 also favoured skills acquisition of business education programme courses respectively as productive.

\subsection{Research question two:}

Which of these qualification holders would you prefer to be defined as a business educator in business education programme? 
Table 2: Mean score of business education teachers' definition of business educator in business education programme

\begin{tabular}{|c|l|c|c|c|c|c|c|c|}
\hline & \multicolumn{1}{|c|}{ Classification } & VHP4 & HP3 & LP2 & VLP1 & Total & Sum & Mean \\
\hline 1 & Person who possesses HND in Business Studies & 2 & 5 & 7 & 6 & 20 & 43 & 2.15 \\
\hline 2 & Person who possesses BSc in Business administration & 4 & 5 & 6 & 5 & 20 & 48 & 2.40 \\
\hline 3 & Person who possesses MSc in Business Studies & 3 & 7 & 5 & 5 & 20 & 48 & 2.40 \\
\hline 4 & Person who possesses MEd in Business Education & 9 & 6 & 5 & 2 & 20 & 62 & 3.10 \\
\hline 5 & Person who possesses an MBA & 4 & 4 & 7 & 5 & 20 & 47 & 2.35 \\
\hline 6 & Person who possesses a PhD in Business Education & 13 & 4 & 2 & 1 & 20 & 69 & 3.45 \\
\hline 7 & Person who possesses a PhD in Economics & 3 & 3 & 8 & 6 & 20 & 43 & 2.15 \\
\hline 8 & Person who possesses a PhD in Educational Management & 5 & 4 & 5 & 6 & 20 & 48 & 2.40 \\
\hline 9 & Person who possesses any other teaching qualification & 2 & 5 & 4 & 9 & 20 & 40 & 2.00 \\
\hline
\end{tabular}

Key: VHP = Very Highly Preferred; HP = Highly Preferred; LP = Less Preferred; VLP = Very Highly Preferred

Table two discusses preference of certificate holders to be defined as business educators. M.Ed business education and Ph.D business education got the highest ratings of 3.10 and 3.45 respectively. While HND in business studies scored 2.15, B.Sc in business administration scored 2.40. As respondents who preferred Ph.D in economics scored 2.15, those who prefer MBA scored 2.35. Those who favoured Ph.D in economics scored 2.40 and those who prefer other teaching qualifications scored 2.00.

\section{Discussions}

The findings in Table one shows that all those items with a mean above 2.50 are productive in teaching and learning of business education programme. By this, the table reveals that knowledge, and skill competencies in computer associated courses, entrepreneurship knowledge and skills, and other business teacher education programme courses are very productive. Invariably, data in the table reveals that knowledge and skills competencies in typewriting, shorthand, educational courses, and economics are not as productive in teaching and learning in business teacher education programme. The implication of this is that these courses with a mean of 2.50 and above have significant influence on teaching and learning in business education programme. Furthermore, the table also reveals that shorthand which is highly regarded in the curriculum with a weightage of 6 credit units in some cases, is the least productive with a score of 1.70. This is in line with the opinion of Marques and Moreira (2013) that students should be introduced to more productive courses than the mundane courses that are no longer relevant in the innovative technological society. This supports Ordu and Mbaba (2012) who underscored the fact that times have come when business education curriculum should be modified to reflect innovations in business and technology.

This result further shows the advent of new thinking about business teacher education programme. Skills that have hitherto been regarded as basic components of communication have been jettisoned by respondents who themselves are teachers of various elements in business education. Furthermore, knowledge of some courses from the general education disciplines and pure management disciplines have also not been favoured. Emphasis seems to be focused on the acquisition of skills in emerging areas of modern times. Going by these data, respondents indicated that business teacher education lecturers need to be competent in teaching and learning of computer associated courses in business teacher education. In this way, only those who are primarily knowledgeable in business teacher education concepts would understand which areas to draw up skills that are relevant in teaching and learning in business teacher education programme. The result of this study supports the provisions of national policy in education (2008) which explains that no nation is greater than the quality of her teachers. This means that a low profile teacher would produce low profile graduates; non-skill teachers in business teacher education programme would produce non-skilled business education graduates; when the knowledge is lacking in the teacher, it is difficult to 
manipulate teaching and learning. Azih (2010) explained that for effective teaching and learning to be achieved, a teacher starts from the known to the unknown, simple to complex, and concrete to abstract. The result of this study is in line with the opinion of Okike (2011) and Ezeani (2013) that for efficiency of students in skills acquisition, there is need to restructure the teaching of entrepreneurship education to integrate practical teaching.

The analysis of data in Table two defines the type of certifications that qualify holders as business educators. Holders of M.Ed. in Business teacher education scored 9 points for Very Highly Preferred with a mean of 3.10 which is above the cut-off point of 2.50. The data reveals that PhD in Business teacher education is highly favoured with 13 points for Very Highly favoured and scoring a mean of 3.45 thereby recording above the cut-off point of 2.50. The possession of any other teaching qualification $2.00, \mathrm{PhD}$ in Economics 2.15, MBAs 2.35, HND business studies 2.15, BSc in Business Administration 2.40, MSc in business studies 2.40, PhD in Educational Management 2.40. The data reveals that holders of these certifications scoring below the cut-off point of 2.50 are not to be addressed as business educators. This means that respondents agree that only holders of qualifications from business teacher education programme have the qualifications to be addressed as business educators.

From the results of the study, it is further observed that those whose certifications are from business teacher education programme have serious challenges in their defense of the curriculum. While this group insists that only those who possess business teacher education qualifications are to be recognized as business educators, it also points that they prefer such people to teach in business teacher education programme as service lecturers nomenclature. This goes to show that teacher preparation from teacher education departments would better be handled by those who had been groomed from such disciplines with adequate foundational knowledge of ocuupational clusters of that discipline. Be that as it may, no programme is isolated in nature. This means that holders of such other certifications outside those from business teacher education programme may be required but at levels that they teach as service-course-providers rather than as traditional business educators, and so in some cases, intimidating those whose qualifications are in business teacher education. This may be associated with the fact that business teacher education curriculum has not been properly implemented leading to what the existence of mundane courses at the expense of innovative measures to align with modern trends. Igbokwe (2010) explained this when he lamented that among other factors, inadequate funding, inappropriate curriculum, chronic dearth of qualified teaches, etc, has made business education programme in Nigeria as a disaster. He therefore recommended among others the revision of curricular offerings to include courses and practical experiences to salvage graduates from unemployment doom. This, accordingly, would ensure that teaching and learning in the programme would focus at meeting the emerging challenges in the relevant industries. The activities of those who possess general education qualifications are largely responsible for the failure of business education programme in Nigeria. The result of this study is in line with the finding of Oduma (2010) that business education programme requires quality teachers who have the competencies to develop their students to adequately prepare and equip them to fit into these new employment markets occationed by technological changes.

\section{Recommendations}

Based on the discussions of findings, the following recommendations are made:

Efforts should be made by institutional administrators to distinguish between business teacher education and general business education disciplines. By so doing, only those whose qualifications mandate them to be employed would be required to teach business teacher education courses and be direct employees of the department to guide teaching and learning.

Furthermore, emerging societal issues are changing the world of work in such a way that only innovative disciplines would survive the economic world. This means that computer courses in business education curriculum should be expanded to include effective learning of computer packages for business 
operations.

It is also necessary that practical entrepreneurship skills, knowledge and business competencies be integrated in course curricular of business teacher education programme. This can only be introduced if creative business educators are employed to teach in business education programme.

It is also necessary that employers of labour in tertiary institutions should know that only qualifications of lecturers relevant to business teacher education should be employed direct into the programme. Since there is no discipline that survives in isolation, lecturers with qualifications that are ancillary to teaching in business teacher education departments should be engaged as service lecturers.

Again, some universities offer all categories of degrees in business teacher education programme. All lecturers who had been employed in business teacher education but do not possess the business teacher education qualifications should be assisted to proceed on further developmental post graduate programme in business teacher education. Those who refuse to develop accordingly should be regarded as stagnant lecturers whose contributions to teaching and learning in the programme are not necessarily required by their qualifications.

\section{Conclusions}

In conclusion, the results of findings show that there are two classes of lecturers in business teacher education programme. One group whose qualifications are in business teacher education programme claim to be authentic business educators whose functions and place of work is being hijacked by others. On the other hand, there is also another group of lecturers engaged in the service of teaching and learning in the programme but their qualifications are from other disciplines. Members of this group also claim to be authorities in the programme by virtue of their teaching and learning over time mainly to keep their jobs. The disparity in understanding flows down to diverse interpretations and poor curriculum implementation in the programme. The paper considers business teacher education programme an area in academics that requires academic sanitation. Teaching and learning in business teacher education programme can help to reduce poverty in Nigeria if curriculum contents are adequately interpreted and implemented. This implementation would lead to what Azih (2010) describes as production of graduates with cognate skills that can help them establish their own business enterprises. This can only be achieved where and only creative business educators have come together.

\section{References}

Akuma, N. and Igu, N. C. N. (2012). Integrating entrepreneurial education into teacher education curriculum. Nigeria Journal Journal of Curriculum Studies, 19 (3): 79-86.

Anioke, B. E. (2013). Towards the changing role of the contemporary office: Challenges of quality assurance in skills development in Colleges of Education. Nigeria Journal of Business Education, 1 (2): 57-67.

Azi, N. (2012). Developing a qualitative entrepreneurial education curriculum in tertiary institutions;: An imperative poverty reduction in Nigeria: An imperative poverty reduction in Nigeria. Nigeria Journal of Curriculum Studies, 19 (2): 94 100

Federal Republic of Nigeria, (2008). National Commission for Colleges of Education. Abuja: TETFUND.

Federal Republic of Nigeria (2004). National Policy on Education (4th ed.), Lagos: NERDC.

Ezeani, N. S. (2013). Business education practices: Mentoring and technology alignments.

Paper presented at the $25^{\text {th }}$ Annual National Conference of Association of Business Educators of Nigeria, Benin, 22-26, October.

Igbokwe, S. A. (2010). Issues in administration and supervision of business teacher education programme in Nigeria. Journal of business and vocational education, 1 (1): 1-8.

Marques, A. P. and Moreira, R. (2013). Traditional and innovative potentials entrepreneurs among Portuguese graduates: A case study. Journal of Educational and Social Research, 3 (7): 134-142. 
Okike, O. N. (2011). Restructuring business education curriculum for entrepreneurship development at tertiary institutional levels. Book of readings, Association of business Educators of Nigeria, 1 (11): 204-208.

Okoli, B. E. (2010). Towards development of entrepreneurship education in business education. Journal of business and vocational education, 1 (1): 20-24.

Ordu, P. (2013). Entrepreneurship: Principles, Methods, Cases. Omoku: JOP Publishers

Ordu, P., and Uduak, G. M. (2012). Nigeria certificate in education entrepreneurship curriculum implementation and students' acquisition of small scale business opportunity skills in South-South geo-political zone of Nigeria. Nigerian Journal of curriculum Studies, 19 (2): 110-119.

Orduma, C. A. (2010). Survey of employers' perception of the professional business competencies needed by business education graduates for gainful employment in organisations. Journal of business and vocational education, 1 (1): 25-39. 